\title{
Synthesis of 1-(1-Arylvinyl)pyridin-2(1H)-ones from Ketones and 2-Fluoropyridine
}

\author{
Takuji Kawamoto, ${ }^{*[a]}$ Shunya Ikeda, ${ }^{[a]}$ and Akio Kamimura ${ }^{[a]}$
}

[a] Dr. Takuji Kawamoto, Shunya Ikeda, Prof. Dr. Akio Kamimura

Department of Applied Chemistry

Yamaguchi University

Ube, Yamaguchi 755-8611, Japan

E-mail: tak102@yamaguchi-u.ac.jp

Supporting information for this article is given via a link at the end of the document.

\begin{abstract}
Pyridone skeletons are found in numerous biologically active molecules and pharmaceuticals. 1-(1-Arylvinyl)pyridin-2(1H)ones are synthetic intermediates derived from the enamide moiety, and only few examples of the synthesis of 1-(1-arylvinyl)-2-pyridones have been reported. In this work, a simple and efficient procedure for the synthesis of $\mathrm{N}$-vinyl-substituted pyridones from ketones and 2fluoropyridine in the presence of trifluoromethane sulfonic anhydride, followed by base treatment is described. Various ketones with electron-donating or -withdrawing groups at the benzene rings can be used in this reaction. A preliminary mechanistic study indicates that it is not very likely that both vinyl triflates and vinyl cations play major roles as intermediates in this transformation. The thus obtained pyridones can be subsequently transformed via $\mathrm{C}-\mathrm{H}$ arylation and radical alkylation reactions.
\end{abstract}

Pyridone, i.e., pyridin-2(1H)-one, skeletons exist in numerous biologically active molecules and pharmaceuticals. ${ }^{1}$ The development of efficient synthetic methods for the straightforward construction of this structural motif has thus received considerable interest from the synthetic community, and several synthetic routes to $\mathrm{N}$-substituted pyridones have been reported. ${ }^{2}$ Although 1-(1-arylvinyl)pyridin-2(1H)-ones are useful synthetic intermediates derived from the enamide moiety, only few examples of the synthesis of 1-(1-arylvinyl)-2-pyridones have been reported. ${ }^{3}$ Undheim and co-workers have reported the reaction of 1-bromophenylacetylene with the sodium salt of 2-pyridinone (eq. 1). ${ }^{4}$ Rao et al. have reported the nucleophilic addition to cyano-substituted aryl alkynes leading to 1-(1arylvinyl)-2-pyridones. ${ }^{5}$

On the other hand, 2-halopydinium salts are easily converted into 2-pyridones. ${ }^{6,7,8}$ Due to the toxicity of 2 -chloropyridine, ${ }^{9}$ the development of efficient synthetic routes to vinyl-2fluoropyridinium salts are highly desirable in order to construct 1 (1-arylvinyl)-2-pyridones. However, the synthesis of 1-(1arylvinyl)-pyridinium salts is still limited. Relles has reported the synthesis of vinyl pyridinium salts from electron-rich acetophenones with $\mathrm{SOCl}_{2}$ using pyridine as the solvent (eq 2). ${ }^{10}$ Novella and Alvarez-Builla have checked the generality of Relles's work. ${ }^{11}$ Substrates with electron-donating groups (e.g., 4-OMe) afford polymers, while substrates with electronwithdrawing groups (e.g., 4-F) do not afford vinyl pyridinium salts Recently, Zhao and co-workers have reported the synthesis of vinyl pyridinium salts from styrenes with fluoropyridinium salts in the presence of an organoselenium catalyst (eq. 3). ${ }^{12}$ Very recently, Majireck has reported the pyridination of alkynes in the presence of $\mathrm{TfOH}$ (eq. 4). However, this system is limited to alkynes that contain electron-donating groups such as OMe, ${ }^{13}$ and pyridinium salts were not observed using phenylacetylene. Trifluoromethanesulfonic anhydride $\left(\mathrm{Tf}_{2} \mathrm{O}\right)$ is a highly electrophilic reagent, ${ }^{14}$ and its reactions with ketones and base furnish vinyl triflates. ${ }^{15}$ Yields can often be improved when using sterically hindered non-nucleophilic bases such as 2,6-di-( $t$ butyl)-4-methylpyridine (DTBMP), ${ }^{16}$ albeit that the latter is relatively expensive. During our study on vinyl triflates, ${ }^{17}$ we obtained $N$-vinyl-substituted pyridinium salts from acetophenones with $\mathrm{Tf}_{2} \mathrm{O}$ in the presence of 2-fluoropyridine ${ }^{18}$ as a mild nucleophilic base. Subsequent treatment of the resulting pyridinium salts under basic conditions furnished 1-(1arylvinyl)pyridin-2(1H)-ones (eq. 5). Herein, we describe the synthesis of 1-(1-arylvinyl)pyridin-2(1H)-ones from acetophenones that contain electron-donating or -withdrawing groups at the benzene ring.

Undheim 1979, Rao 1989<smiles>CC(C)(C)C#Cc1ccccc1</smiles>

$\mathbf{R}=\mathrm{H}, \mathrm{EWG}=\mathrm{Br}$

$\mathbf{R}=4-\mathrm{Cl}, 4-\mathrm{OMe}, \mathrm{EWG}=\mathrm{CN}$

Relles 1973 and Novella 1985

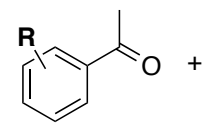

$\mathbf{R}=\mathrm{H}, 4-\mathrm{Me}$ 4-Cl, 4-Br, etc

Zhao 2017<smiles>C=Cc1ccccc1</smiles>

$\mathbf{R}=\mathrm{H}, 4-\mathrm{Me}, 4-\mathrm{OMe}$ $4-\mathrm{F}, 4-\mathrm{Cl}, 4-\mathrm{Br}$, etc.

Majireck 2019<smiles>C#Cc1ccccc1</smiles><smiles>Clc1ccccn1</smiles>

$\mathbf{R}=4-\mathrm{OMe}$

This Work<smiles>CC(=O)c1ccccc1</smiles><smiles>Fc1ccccn1</smiles><smiles>CCCCCCCO</smiles><smiles></smiles>

$\mathbf{R}=4-\mathrm{OMe}, 4-\mathrm{CO}_{2} \mathrm{Me}, 4-\mathrm{CN}$ 4-F, 4-Cl, 4-Br, etc. 
For our initial study, we chose 4'-chloroacetophenone (1a) as a model substrate (Table 1). When a $\mathrm{CH}_{2} \mathrm{ClCH}_{2} \mathrm{Cl}$ solution of $1 \mathrm{a}$, 2-fluoropyridine (2a) (1.0 equiv), and $\mathrm{Tf}_{2} \mathrm{O}$ (1.5 equiv) was stirred for $1 \mathrm{~h}$ at $80^{\circ} \mathrm{C}$, and subsequently treated with $\mathrm{NaOH}$ aq., vinyl triflate $3 \mathrm{a}$ was obtained in $92 \%$ yield together with vinyl pyridone $\mathbf{4 a a}$ in $4 \%$ yield (Table 1 , entry 1 ). Increasing the amount of $\mathbf{2 a}$ to e.g. 3.0 equiv resulted in the formation of $4 \mathbf{a a}$ in $79 \%$ yield after column chromatography on silica gel (entry 3 ). Table 1. Initial Study<smiles>CC(=O)c1ccc(Cl)cc1</smiles>

1a
1) $\mathrm{Tf}_{2} \mathrm{O}$ (1.5 equiv) $\mathrm{CH}_{2} \mathrm{ClCH}_{2} \mathrm{Cl}(1 \mathrm{~mL})$<smiles>Fc1ccccn1</smiles>
2) $1 \mathrm{M} \mathrm{NaOH}$ aq.<smiles>C=C([O])c1ccc(Cl)cc1</smiles><smiles>C=C(c1ccc(Cl)cc1)n1ccccc1=O</smiles>

\begin{tabular}{|c|c|c|c|c|}
\hline \multicolumn{5}{|c|}{$3 a$} \\
\hline entry & $2 a$ (equiv) & conv. of $1 \mathbf{a}^{[a]}$ & $3 \mathbf{a}^{[\mathrm{a]}}$ & $\mathbf{4} \mathbf{a a}{ }^{[a, b]}$ \\
\hline 1 & 1.0 & $97 \%$ & $92 \%$ & $4 \%$ \\
\hline 2 & 2.0 & $86 \%$ & $42 \%$ & $53 \%$ \\
\hline 3 & 3.0 & $99 \%$ & $5 \%$ & $93 \%(7 \subseteq$ \\
\hline
\end{tabular}

[a] Determined by ${ }^{1} \mathrm{H}$ NMR spectroscopy using 1,1,2,2-tetrachloroethane as an internal standard. [b] The isolated product yield, after flash column chromatography on $\mathrm{SiO}_{2}$, is given in parentheses.

With the optimized conditions (Table 1, entry 3 ) in hand, we next examined the substrate scope for the synthesis of vinyl pyridones and the results are summarized in Table 2. Halosubstituted acetophenones $\mathbf{1 a - 1 f}$ afforded $\mathbf{4 a a}-\mathbf{4 f a}$ in good yield (entries 1-6). The reaction of acetophenone (1 $\mathbf{g})$ furnished vinyl pyridone $\mathbf{4 g a}$ in $85 \%$ yield (entry 7 ). p-Methoxy-, o-methyl-, and $p$-phenyl-substituted acetophenones also worked well (entries 8-10). Substrates with electron-withdrawing groups at the benzene ring $(\mathbf{1 k}-\mathbf{1 m})$ afforded the corresponding products (4ka-4ma) in moderate to good yield (entries 11-13). For example, the reaction of 1-(4-(methylsulfonyl)phenyl)ethan-1one (1I) furnished $4 \mathrm{la}$ in $52 \%$ yield (entry 12). Increasing the proportion of 4 -fluoropyridine (2a) to 5 equiv generated vinyl pyridone $4 \mathrm{la}$ in $64 \%$ yield (entry 13$)$. 1-(Naphthalen-1-yl)ethan-1one (1n) and 2-(naphthalen-1-yl)ethan-1-one (10) also worked well (entries 16 and 17). The reaction of 1 f and 2-fluoro-4methylpyridine (2b) with $\mathrm{Tf}_{2} \mathrm{O}$ gave the corresponding pyridine (4fb) in good yield (entry 18). The reaction of 1-(4chlorophenyl)propan-1-one (1p) and 1,2-diphenylethan-1-one (1q) afforded the corresponding products with high stereoselectivity in $83 \%$ and $60 \%$ yield, respectively (entries 19 and 20). The present synthesis of vinyl pyridones can also be carried out on the gram scale, furnishing $\mathbf{4 f a}$ in $88 \%$ yield and 4ha in $97 \%$ yield (eq. 3 and 4 ).

Table 2. Substrate Scope ${ }^{[a]}$

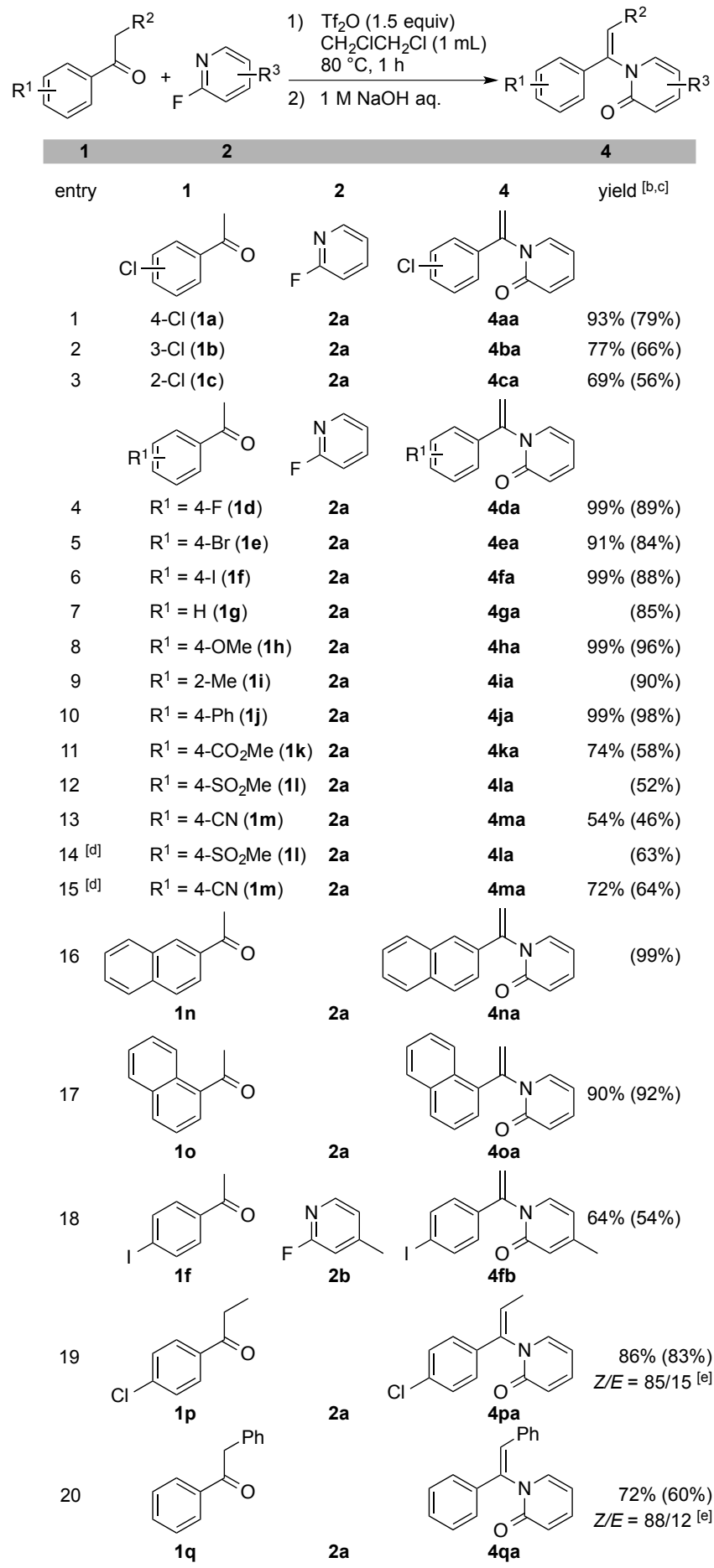

[a] 1 (0.5 mmol), 2 (1.5 mmol, 3 equiv), $\mathrm{Tf}_{2} \mathrm{O}$ (1.5 equiv), $\mathrm{CH}_{2} \mathrm{ClCH}_{2} \mathrm{Cl}(2 \mathrm{~mL})$, $80{ }^{\circ} \mathrm{C}, 1 \mathrm{~h}$. [b] Determined by ${ }^{1} \mathrm{H}$ NMR spectroscopy using $1,1,2,2-$ tetrachloroethane as the internal standard. [c] The isolated product yield, after flash column chromatography on $\mathrm{SiO}_{2}$, is given in parentheses. [d] $2 \mathrm{a}$ (5 equiv) was used. [e] The stereoselectivity was determined by ${ }^{1} \mathrm{H}$ NMR analysis of the crude reaction mixture. 


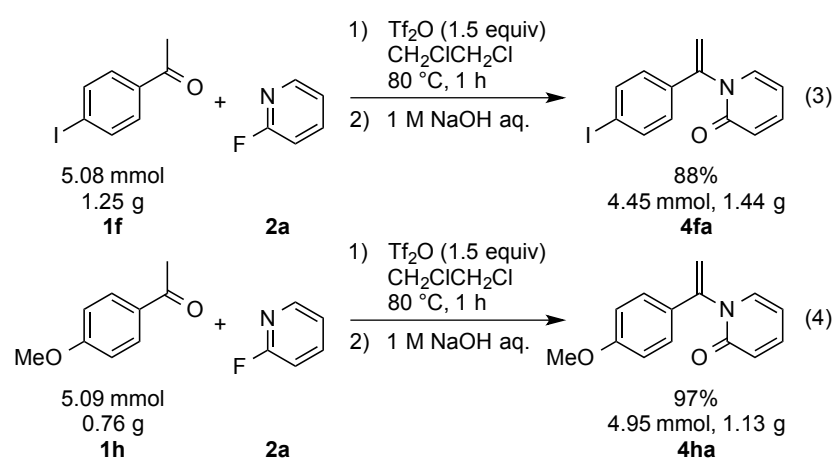

According to previous work on vinyl triflates by other groups, vinyl triflates that contain electron-donating groups at the para position of the benzene ring easily afford vinyl cations, which can be trapped by nucleophiles such as nitriles ${ }^{19}$ or sulfoxides. ${ }^{20}$ Therefore, we examined the reaction using vinyl triflates $\mathbf{3 a}, \mathbf{3 g}$, and $\mathbf{3 k}$ or aryl alkynes $\mathbf{1} \mathbf{h}^{\prime}, \mathbf{1} \mathbf{g}^{\prime}$, and $\mathbf{1} \mathbf{k}^{\prime}$ to gain mechanistic insights. When a $\mathrm{CH}_{2} \mathrm{ClCH}_{2} \mathrm{Cl}$ solution of $\mathbf{3 a}, \mathbf{3 g}$, and $\mathbf{3 k}$ and 2fluoropyridine was stirred at $80^{\circ} \mathrm{C}$ for $1 \mathrm{~h}$, followed by treatment with $\mathrm{NaOH}$ aq., the desired product was obtained in $1 \%, 12 \%$, and $0 \%$ yield, respectively. Similar to the result of Majireck et al., エラー! ブックマークが定義されていません。 ${ }^{\mathrm{b}}$ the reaction of aryl alkynes 19' and 1 $\mathbf{1}$ ' with $\mathrm{TfOH}$ and 2-fluoropyridine did not afford vinyl pyridones effectively. These results suggest that it is not very likely that both vinyl triflates (3) and vinyl cations play major roles as intermediates in this transformation (Scheme 1).

Scheme 1. Control experiments<smiles>[R]c1ccc(C(=C)[O])cc1</smiles>

3<smiles>Fc1ccccn1</smiles>
$2 a$
3 equiv 1) $\mathrm{CH}_{2} \mathrm{ClCH}_{2} \mathrm{Cl}$ $80^{\circ} \mathrm{C}, 1 \mathrm{~h}$ 2) $1 \mathrm{M} \mathrm{NaOH}$ aq.<smiles>[R]c1ccc(C(=C)n2ccccc2=O)cc1</smiles>
$\mathrm{R} \quad 4$ $\mathrm{Cl}(\mathbf{3 a})$ $\mathrm{H}(\mathbf{3 g})$ $\mathrm{CO}_{2} \mathrm{Me}(\mathbf{3 k})$

1) $\mathrm{TfOH}$ (1 equiv) $\mathrm{CH}_{2} \mathrm{ClCH}_{2} \mathrm{Cl}$<smiles>[R]c1ccc(C#C)cc1</smiles>

$1^{\prime}$<smiles>Fc1ccccn1</smiles>
$2 a$ 2) $1 \mathrm{M} \mathrm{NaOH}$ aq.<smiles>[R]c1ccc(C(=C)n2ccccc2=O)cc1</smiles>

When a pyridinium salt, which was obtained from treating 2fluoropyridine (2a) with $\mathrm{Tf}_{2} \mathrm{O}$, ${ }^{18 \mathrm{~d}}$ in $\mathrm{CDCl}_{3}$ was exposed to acetophenone $1 \mathrm{a}(4-\mathrm{Cl})$ or $1 \mathrm{~h}(4-\mathrm{OMe})$ at $\mathrm{rt}$ for $1 \mathrm{~h}$, the corresponding vinyl pyridinium salts were generated.

Although the details of the underlying mechanism still remain unclear at this stage, a plausible mechanism is shown in Scheme 2. The generated trifluoromethanesulfonyl pyridinium salt reacts with a ketone via a concerted pathway to give pyridinium intermediate A. Another 2-fluoropyridine abstracts a proton to give vinyl pyridinium $\mathbf{B}$, which undergoes hydrolysis to furnish the final product. An alternative mechanism is based on Neuhoff's work. ${ }^{21}$ The reaction of acetophenone with $\mathrm{Tf}_{2} \mathrm{O}$ gives carbocation intermediate, which is trapped by 2 -fluoropyridine to afford pyridinium intermediate $\mathbf{A}$.

Scheme 2. Plausible reaction mechanism for the synthesis of 1-(1arylvinyl)pyridin-2(1H)-ones from ketones and 2-fluoropyridine

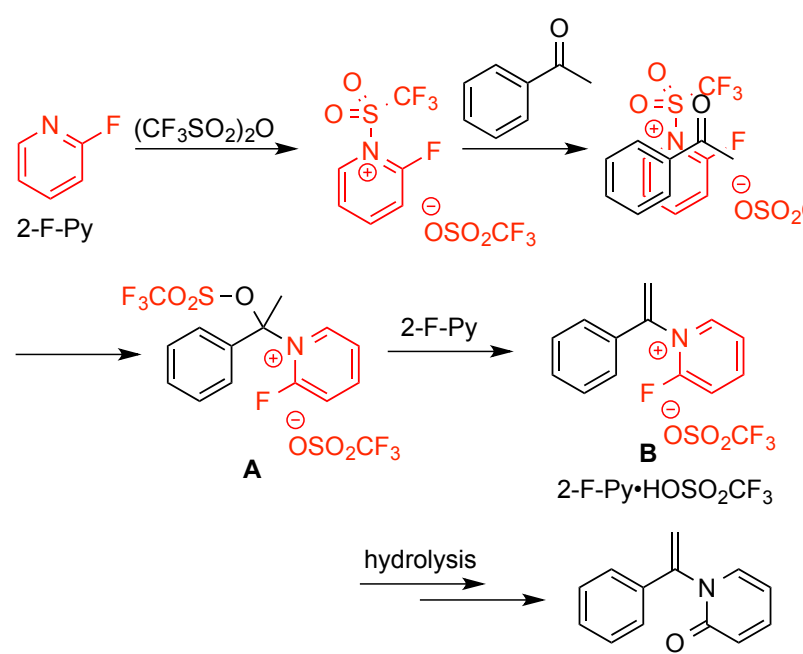

As the products contain enamide moieties, they are amenable to further transformations (Scheme 3). For example, a palladiumcatalyzed $\mathrm{C}-\mathrm{H}$ arylation reaction ${ }^{22}$ of $\mathbf{4}$ ha with aryl iodide $\mathbf{5}$ forms trisubstituted alkene 6 ha in $81 \%$ yield. A black-lightinduced Heck-type reaction with bromomalonate furnished the corresponding alkylated product (8ha) in $56 \%$ yield.

Scheme 3. Subsequent transformation of the obtained vinyl pyridones

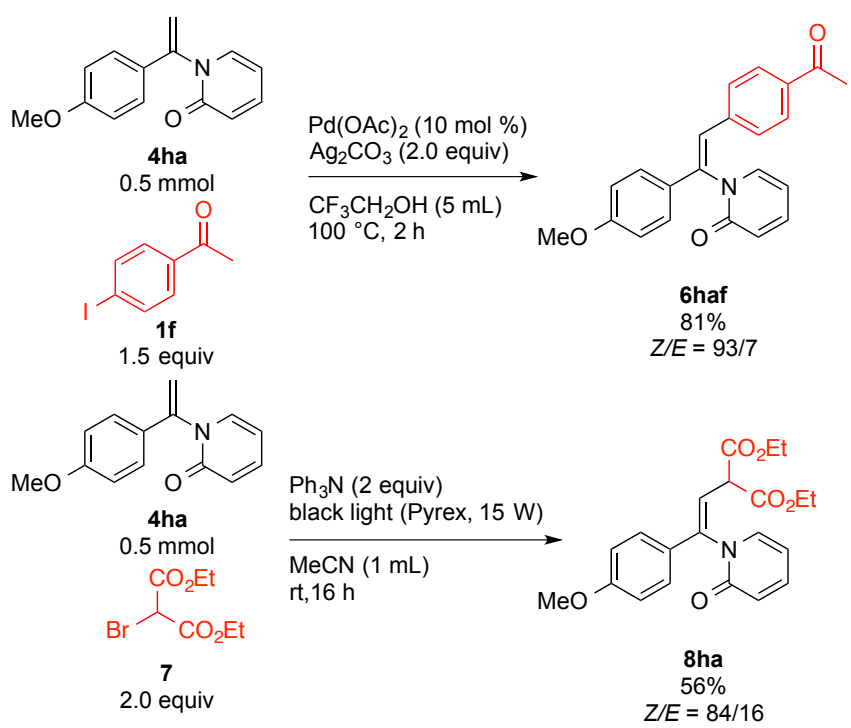

In summary, we have developed a synthetic route to vinyl pyridones from acetophenones and 2-fluoropyridine with $\mathrm{Tf}_{2} \mathrm{O}$ as an activator. This strategy is characterized by an excellent functional-group tolerance and procedural simplicity. The generated vinyl pyridones are easily transformed via $\mathrm{C}-\mathrm{H}$ arylation and radical alkylation reactions. Further mechanistic studies are currently in progress and the corresponding results will be reported in due course. 


\section{Acknowledgements}

This work was partially supported by a JSPS Grant-in-Aid for Young Scientists (B) (18K14222), the Yamagin Regional Enterprise Support Foundation, and the Tobe Maiki Scholarship Foundation. The authors would like to thank Central Glass Co., Ltd. (Japan) for a generous gift of $\mathrm{Tf}_{2} \mathrm{O}$.

Keywords: Ketones • Vinyl Pyridones • Vinyl Pyridinium • Cations $\cdot \mathrm{Tf}_{2} \mathrm{O}$

1 (a) S. Hibi, K. Ueno, S. Nagato, K. Kawano, K. Ito, Y. Norimine, O. Takenaka, T. Hanada, M. Yonaga, J. Med. Chem. 2012, 55, 10584 10600. (b) L. Li, X. Jiang, S. Huang, Z. Ying, Z. Zhang, C. Pan, S. Li, X Wang, Z. Zhang, ACS Med. Chem. Lett. 2017, 8, 407-412. (c) R. M. Cox, M. Toots, J.-J. Yoon, J. Sourimant, B. Ludeke, R. Fearns, J. Patti, E. Lee, J. Vernachio, R. K. Plemper, et al., J. Biol. Chem. 2018, 293 16761-16777. (d) Z. Wang, Z. Yu, D. Kang, J. Zhang, Y. Tian, D Daelemans, E. De Clercq, C. Pannecouque, P. Zhan, X. Liu, Bioorg Med. Chem. 2019, 27, 447-456. (e) R. Ettari, C. Cerchia, S. Maiorana, M. Guccione, E. Novellino, A. Bitto, S. Grasso, A. Lavecchia, M. Zappalà, ChemMedChem 2019, 14, 842-852. (f) V. Namasivayam, M. Vanangamudi, V. G. Kramer, S. Kurup, P. Zhan, X. Liu, J. Kongsted, S. N. Byrareddy, J. Med. Chem. 2019, 62, 4851-4883. (g) S. Dorich, J. H. Cox, J. D. Burch, F. Chagnon, Bin Chen, S. Léger, M. St-Onge, L. D Fader, Bioorg. Med. Chem. Lett. 2020, 30, 127104.

2 For selected synthetic routes to $N$-substituted 2-pyridones, see: (a) J. Hillenbrand, W. S. Ham, T. Ritter, Org. Lett. 2019, 21, 5363-5367. (b) M. Kuriyama, N. Hanazawa, Y. Abe, K. Katagiri, S. Ono, K. Yamamoto, O. Onomura, Chem. Sci. 2020, 11, 8295-8300.

3 C. Sun, X. Qi, X.-L. Min, X.-D. Bai, P. Liu, Y. He, Chem. Sci. 2020, 11, 10119-10126.

4 H. Breivik, T. Ottersen, K. Undheim, Acta Chem. Scand B. 1979, 33, 365-369.

5 R. Yadla, H. Rehman, J. M. Rao, V. K. Mahesh, Tetrahedron 1989, 45 7093-7098.

6 (a) T. Mukaiyama, M. Usui, E. Shimada, K. Saigo, Chem. Lett. 1975, 4, 1045-1048. (b) E. Bald, K. Saigo, T. Mukaiyama, Chem. Lett. 1975, 4 , 1163-1166.

7 (a) T. Mukaiyama, S. Ikeda, S. Kobayashi, Chem. Lett. 1975, 4, 11591162. (b) S. Kobayashi, M. Tsutsui, T. Mukaiyama, Chem. Lett. 1976, 5, 373-374. (a) G. Hu, J. Xu, P. Li, Org. Biomol. Chem. 2018, 16, 4151-4158. () C. Liao, J. Li, X. Chen, J. Lu, Q. Liu, L. Chen, Y. Huang, Y. Li, Org. Biomol. Chem. 2020, 18, 1185-1193.

9 P. J. Gehring, T. R. Torkelson, F. Oyen, Toxicol. Appl. Pharmacol. 1967, 11, 361-371.

10 H. M. Relles, J. Org. Chem. 1973, 38, 1570-1574.

11 J. L. Novella, J. Alvarez-Builla, Anales de Quimica, Serie C: Quimica Organica y Bioquimica 1985, 81, 186-187.

12 L. Liao, R. Guo, X. Zhao, Angew. Chem., Int. Ed. 2017, 56, 3201-3205.

13 (a) A. M. Blades, D. L. McConnell, D. Gomes Rodrigues, P. V. Keyes, J. C. Sonberg, C. E. Anthony, S. Rachad, O. M. Simone, C. F. Sullivan, J. D. Shapiro, C. C. Williams, B. C. Schafer, J. A. Goodman, M. Majireck, Chemrxiv, 2019. DOI: 10.26434/chemrxiv.7381952.v1 (b) J. Shapiro, J. Sonberg, B. Schafer, C. Williams, H. Ferris, E. Reinheimer, A. Van Wynsberghe, C. Kriley, M. Majireck, Molecules 2018, 23, 413-14.

14 A. G. Martinez, L. R. Subramanian, M. Hanack, S. J. Williams, S. Régnier, (2016) Trifluoromethanesulfonic Anhydride. In Encyclopedia of Reagents for Organic Synthesis. John Wiley: New York, 2016, DOI: 10.1002/047084289X.rt247.pub3

15 (a) K. Ritter, Synthesis 1993, 1993, 735-762. (b) I. L. Baraznenok, V. G. Nenajdenko, E. S. Balenkova, Tetrahedron 2000, 56, 3077-3119.

16 P. J. Stang, W. Treptow, Synthesis 1980, 283-284.

17 (a) T. Kawamoto, R. Sasaki, A. Kamimura, Angew. Chem., Int. Ed. 2017, 56, 1342-1345. (b) T. Kawamoto, R. Sasaki, A. Kamimura, H. Matsubara, J. Fluorine. Chem. 2019, 221, 66-69.

18 For selected examples of the activation of amides using $\mathrm{Tf}_{2} \mathrm{O}$ and 2fluoropyridine, see: (a) J. W. Medley, M. Movassaghi, J. Org. Chem. 2009, 74, 1341-1344. (b) W. S. Bechara, G. Pelletier, A. B. Charette Nature Chem. 2012, 4, 228-234. (c) K.-J. Xiao, A.-E. Wang, P.-Q. Huang, Angew. Chem., Int. Ed. 2012, 51, 8314-8317. (d) B. Peng, D. Geerdink, C. Farès, N. Maulide, Angew. Chem., Int. Ed. 2014, 53, 5462-5466. (e) K. L. White, M. Mewald, M. Movassaghi, J. Org. Chem. 2015, 80, 7403-7411.

19 A. G. Martinez, A. Herrera, R. Martinez, E. Teso, A. Garcia, J. Osio, L. Pargada, R. Unanue, L. R. Subramanian, M. Hanack, J. Heterocycl. Chem. 1988, 25, 1237-1241.

20 W. Zawodny, C. J. Teskey, M. Mishevska, M. Völkl, B. Maryasin, L. González, N. Maulide, Angew. Chem., Int. Ed. 2020, 59, 20935-20939.

21 For the synthesis of pyridinium salts from $\alpha, \beta$-unsaturated ketones with $\mathrm{POCl}_{3}$, see: E. Müller, A. Langerbeck, H. Neuhoff, Ber. Dtsch. Chem. Ges. A/B 1944, 141-152.

22 W. Zhang, W. Yu, Q. Yan, Z. Liu, Y. Zhang, Org. Chem. Front. 2017, 4, 2428-2432. 


\section{Entry for the Table of Contents}

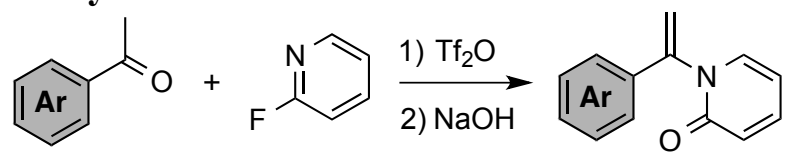

The synthesis of 1-(1-arylvinyl)-2-pyridones from ketones and 2-fluoropyridine with $\mathrm{Tf}_{2} \mathrm{O}$ as an activator is described. This strategy is characterized by an excellent functional-group tolerance and procedural simplicity. The generated vinyl pyridones can be easily transformed via $\mathrm{C}-\mathrm{H}$ arylation and radical alkylation reactions. 